\title{
Pharmacological Characterization of the Native Store-Operated Calcium Channels of Cortical Neurons from Embryonic Mouse Brain
}

\author{
Sylvain Chauvet ${ }^{1,2,3}$, Louis Jarvis ${ }^{1,2,3}$, Mireille Chevallet ${ }^{1,2,3}$, Niroj Shrestha ${ }^{4}$, \\ Klaus Groschner ${ }^{4}$ and Alexandre Bouron ${ }^{1,2,3 *}$ \\ ${ }^{1}$ UMR CNRS 5249, Commissariat à l'Énergie Atomique et aux Énergies Alternatives, Grenoble, France, ${ }^{2}$ Université \\ Grenoble Alpes, Grenoble, France, ${ }^{3}$ Institut de Biosciences et Biotechnologies de Grenoble - Laboratoire de Chimie et \\ Biologie des Métaux, Grenoble, France, ${ }^{4}$ Institute of Biophysics, Medical University of Graz, Graz, Austria
}

In the murine brain, the first post-mitotic cortical neurons formed during embryogenesis express store-operated channels (SOCs) sensitive to Pyr3, initially proposed as a blocker of the transient receptor potential channel of $\mathrm{C}$ type 3 (TRPC3 channel). However, Pyr3 does not discriminate between Orai and TRPC3 channels, questioning the contribution of TRPC3 in SOCs. This study was undertaken to clarify the molecular identity and the pharmacological profile of native SOCs from E13 cortical neurons. The mRNA expression of STIM1-2 and Orai1-3 was assessed by quantitative reverse transcription polymerase chain reaction. E13 cortical neurons expressed STIM1-2 mRNAs, with STIM2 being the predominant isoform. Only transcripts of Orai2 were found but no Orai1 and Orai3 mRNAs. Blockers of Orai and TRPC channels (Pyr6, Pyr10, EVP4593, SAR7334, and GSK-7975A) were used to further characterize the endogenous SOCs. Their activity was recorded using the fluorescent $\mathrm{Ca}^{2+}$ probe Fluo-4. Cortical SOCs were sensitive to the Orai blockers Pyr6 and GSK-7975A, as well as to EVP4593, zinc, copper, and gadolinium ions, the latter one being the most potent SOCs blocker tested $\left(\mathrm{IC}_{50} \sim 10 \mathrm{nM}\right)$. SOCs were insensitive to the TRPC channel blockers Pyr10 and SAR7334. In addition, preventing mitochondrial $\mathrm{Ca}^{2+}$ uptake inhibited SOCs which were unaffected by inhibitors of the $\mathrm{Ca}^{2+}$-independent phospholipase $\mathrm{A}_{2}$. Altogether, Orai2 channels are present at the beginning of the embryonic murine cortico-genesis and form the core component of native SOCs in the immature cortex. This $\mathrm{Ca}^{2+}$ route is likely to play a role in the formation of the brain cortex.

Keywords: store-operated channels, calcium, Orai channels, neurons, cortex

\section{INTRODUCTION}

Store-operated channels (SOCs) are $\mathrm{Ca}^{2+}$-conducting channels of the plasma membrane (PM) that open in response to the emptying of a pool of $\mathrm{Ca}^{2+}$ stored in the endoplasmic reticulum (ER). SOCs mediate a prominent $\mathrm{Ca}^{2+}$ signaling process called store-operated $\mathrm{Ca}^{2+}$ entry (SOCE), initially named capacitative $\mathrm{Ca}^{2+}$ entry (CCE; Putney, 1986). Although neurons express numerous types of $\mathrm{Ca}^{2+}$-conducting channels, which could make this pathway redundant or even unnecessary, they nevertheless exhibit a SOCE. The first studies providing experimental evidence for the existence of a putative neuronal SOCE appeared nearly 25 years ago. They 
were carried out on cells lines (N1E-115 and PC12 cells) and showed that the passive leakage of $\mathrm{Ca}^{2+}$ out of the ER induced by the sarco/endoplasmic $\mathrm{Ca}^{2+}$ ATPase (SERCA) inhibitor thapsigargin is associated with an influx of $\mathrm{Ca}^{2+}$ (Takemura et al., 1991; Clementi et al., 1992; Mathes and Thompson, 1994). Since then, SOCE has been observed in diverse neuronal preparations including cultured dorsal root ganglion neurons (Usachev and Thayer, 1999), freshly dissociated olfactory receptor neurons (Zufall et al., 2000), cultured hippocampal (Bouron, 2000), and cortical neurons (Prothero et al., 2000; Yoo et al., 2000).

The current molecular description of SOCE proposes that SOCs consist of Orai channels recruited by STIM (Stromal interaction molecules), a family of $\mathrm{Ca}^{2+}$ sensors of the ER. To date, two STIM (STIM1-2) and three Orai (Orai1-3) isoforms are known (Hoth and Niemeyer, 2013; Prakriya and Lewis, 2015). But whether this STIM/Orai complex is necessary and sufficient to fully reconstitute native SOCs is still an open question. Indeed, some authors propose a more complex scenario with additional actors such as transient receptor potential channels of $\mathrm{C}$ type (TRPC channels). According to this latter view, STIM, Orai, and TRPC would be necessary to generate a SOCE (Birnbaumer, 2009; Lee et al., 2010; Cheng et al., 2013).

In the murine brain, the onset of cortico-neurogenesis occurs at $\sim$ E12 (Takahashi et al., 1995). Since $\mathrm{Ca}^{2+}$ signaling plays a critical role in cortical development, it is important to understand how the first post-mitotic neurons acquire this essential cation. $\mathrm{Ca}^{2+}$ imaging experiments revealed that murine E13 cortical neurons display a SOCE (Bouron et al., 2005; Gibon et al., 2010) that is inhibited by Pyr3 with an $\mathrm{IC}_{50}$ of $\sim 0.5 \mu \mathrm{M}$ (Gibon et al., 2010), a pyrazole derivative originally described as a selective TRPC3 channels inhibitor (Kiyonaka et al., 2009). This finding suggested that TRPC3 channels could be critical components of native SOCs in cortical neurons. However, subsequent studies found that Pyr3 does not discriminate between TRPC3 and Orail since it blocks these channels with the same potency (Schleifer et al., 2012), leaving some doubt on the contribution of TRPC3 in SOCE of embryonic cortical neurons. Therefore, the following study was undertaken to better characterize the molecular identity as well as the pharmacological profile of native SOCs from E13 cortical neurons.

\section{MATERIALS AND METHODS}

\section{Animal and Ethical Statement}

The C57Bl6/J mice used in this study were from the Jackson Laboratory (USA). They were housed in temperature-controlled rooms under a $12 \mathrm{~h}$ light - $12 \mathrm{~h}$ dark cycle with ad libitum access to food and water. Two females were housed per cage whereas males were kept individually. In each instance, they were permanently exposed to an enriched environment in accordance with the Animal Welfare Committee of the CEA Grenoble. They were crossed once a week which allowed us to determine the age of the embryos. Pregnant mice were killed by cervical dislocation without prior anesthesia. The use of animals and all procedures were approved by the animal care committee of the CEA's Life Sciences Division (CEtEA; \# A14-006).

\section{Materials}

SAR7334 and GSK-7975A were kind gifts from SanofiAventis Deutschland and Dr. Malcolm Begg (GlaxoSmithKline), respectively. All the reagents were from Sigma-Aldrich (France, Austria) except for Fluo-4/AM, Fura-2/AM, and tissue culture media from Molecular Probes, Invitrogen (France, Austria).

\section{Cell Cultures of Cortical Neuron and RBL-2H3}

Primary cultures of cortical neurons were prepared from E13 embryos according to experimental procedures described in Gibon et al. (2013) and Chauvet et al. (2015). Briefly, following removal of the meninges, ganglionic eminences, and olfactory bulbs, cerebral cortices of E13 mice (with the vaginal plug as E0) were isolated from 5 to 6 embryos and placed in $1 \mathrm{~mL}$ of an ice-cold $\mathrm{Ca}^{2+}$ - and $\mathrm{Mg}^{2+}$-free Hank's solution supplemented with $33 \mathrm{mM}$ glucose, $4.2 \mathrm{mM} \mathrm{NaHCO} 3,10 \mathrm{mM}$ HEPES, and $1 \%$ penicillin/streptomycin. Cortical cells were dissociated by mechanical trituration using a sterile Pasteur pipette. The cell suspension was filtered through a $40 \mu \mathrm{m}$ cell strainer and isolated cells were plated at a density of $\sim 1.5 \times 10^{5}$ cells $/ 16 \mathrm{~mm}$ diameter glass coverslips before being placed into $35 \mathrm{~mm}$ diameter petri dishes containing $2 \mathrm{~mL}$ of a Neurobasal medium supplemented with B27 (2\%) and glutamine (500 $\mu \mathrm{M}$; Gibon et al., 2013). RBL-2H3 cells were cultured in Dulbecco's Modified Eagle Medium (DMEM) containing 10\% fetal bovine serum, $100 \mathrm{U} / \mathrm{mL}$ penicillin, and $100 \mu \mathrm{g} / \mathrm{mL}$ streptomycin. Cells were maintained in an incubator at $37^{\circ} \mathrm{C}$ in $5 \% \mathrm{CO}_{2}$ atmosphere.

\section{Quantitative PCR}

RNA from cortex and isolated neuron cells were isolated using Absolutely RNA miniprep kit (Agilent \# 400800). RNA concentration was determined using a NanoDrop spectro photometer (ND-1000). Reverse transcription was performed with the Affinity script qPCR cDNA synthesis kit (Agilent \# 600559) according to the manufacturer's instructions. Gene specific primers for the different STIM and Orai murine genes were designed according to the primer software Primer-Blast. The designed primers are given in Table 1. Quantitative PCR was performed with Brilliant II SYBR green qPCR master mix1 (Agilent \# 600828) using primers at $200 \mathrm{nM}$. PCR reaction mixtures $(10 \mu \mathrm{l})$ were placed in a Cfx96 instrument (Bio-Rad) where they underwent the following cycling program, optimized for a 96 -well block: $95^{\circ} \mathrm{C}$ for $15 \mathrm{~min}$, immediately followed by 40 cycles of $10 \mathrm{~s}$ at $95^{\circ} \mathrm{C}$ and $30 \mathrm{~s}$ at $60^{\circ} \mathrm{C}$. At the end, PCR

TABLE 1 | List of the primer sequences used for the quantitative PCR.

\begin{tabular}{lll}
\hline Gene & Forward primer sequence & Reverse primer sequence \\
\hline Orai 1 & cctggcgcaagctctactta & catcgctaccatggcgaagc \\
Orai 2 & gtgggtctcatcttcgtggt & tcttcgatctcacggttgtg \\
Orai 3 & tgcactgatggtctccacat & tgcactgatggtctccacat \\
STIM 1 & ttgggcctcctctcttgact & gccacccacaccaataacga \\
STIM 2 & aatcagcgaccgaagtcaca & ttatgaggtgggcgtgtcag \\
TRPC 1 & aagctttcttgctggcgtg & ctcccaagcacatctacgca
\end{tabular}


products were dissociated by incubating for $1 \mathrm{~min}$ at $95^{\circ} \mathrm{C}$ and then $30 \mathrm{~s}$ at $55^{\circ} \mathrm{C}$, followed by a ramp up to $95^{\circ} \mathrm{C}$. PCR quality and specificity were verified by analyzing the dissociation curve. qRT-PCR reactions were run in triplicate, and quantification was performed using comparative regression ( $\mathrm{Cq}$ determination mode). Quantitative PCR data were comparatively analyzed according to Pfaffl (2001) with $18 \mathrm{~S}$ as reference gene. Results are expressed as relative quantity of mRNA.

\section{Time-Lapse $\mathbf{C a}^{2+}$ Imaging Experiments}

The experimental setup was as described in Gibon et al. (2010), Tu et al. (2010), and Chauvet et al. (2015). Briefly, cells were incubated for $20 \mathrm{~min}$ at room temperature in the dark in a saline consisting of (in $\mathrm{mM}$ ): $136 \mathrm{NaCl}, 5 \mathrm{KCl}, 2 \mathrm{CaCl}_{2}, 1 \mathrm{MgCl}_{2}, 10$ HEPES, 10 glucose, pH $7.4(\mathrm{NaOH})$ supplemented with $1.25 \mu \mathrm{M}$ Fluo-4/AM. After dye loading, cells were rinsed twice and kept $10 \mathrm{~min}$ at room temperature in the dark before recording Fluo-4 responses. To this aim, the baseline Fluo- 4 fluorescence was recorded for $\geq 1 \mathrm{~min}$ and averaged (F0). The results are expressed as F/F0 as a function of time, with F being the Fluo4 fluorescence intensity. Each solution was prepared fresh each day from $1000 \times$ stock solutions so that the final concentration of DMSO never exceeded $0.1 \%$. Images were acquired at room temperature at a frequency of $0.2 \mathrm{~Hz}$ with a CCD CoolSnap HQ2 camera (Princeton Instruments, Roper Scientific, France) placed on an inverted Axio Observer A1 microscope (Carl Zeiss, France) having a Fluar $40 \times$ oil immersion objective lens (1.3 NA, Carl Zeiss, France). A DG-4 wavelength switcher (Princeton Instruments, Roper Scientific, France) was used. The excitation light for Fluo-4 was filtered through a 470-495 nm excitation filter and the light was collected through a $525 \mathrm{~nm}$ filter. Data acquisition and off-line analysis were conducted with MetaFluor (version 7.0, Universal Imaging, Roper Scientific, France). All of the live cell $\mathrm{Ca}^{2+}$ imaging experiments were conducted on cultured neurons at 2-3 days in vitro.

Changes in $\left[\mathrm{Ca}^{2+}\right]_{\mathrm{i}}$ in RBL-2H3 cells were monitored using the Fura-2 technique as previously described (Schleifer et al., 2012). Cells grown on coverslips at a confluency of $50-60 \%$ were incubated in a saline consisting of (in $\mathrm{mM}$ ): $136 \mathrm{NaCl}, 5$ $\mathrm{KCl}, 2 \mathrm{CaCl}_{2}, 1 \mathrm{MgCl}_{2}, 10$ HEPES, 10 glucose, pH $7.4(\mathrm{NaOH})$ supplemented with $2 \mu \mathrm{M}$ Fura-2 AM for $40 \mathrm{~min}$ at room temperature in the dark. After the incubation period, cells were washed twice with saline and left to equilibrate for at least $20 \mathrm{~min}$. The coverslip was then mounted in a perfusion chamber on an inverted microscope (Olympus IX71) and perfused with different solutions at room temperature. During the recordings using Live Acquisition 2.5 software (FEI, Germany), cells were excited alternately at 340 and $380 \mathrm{~nm}$ using an Oligochrome excitation system (FEI, Germany) and fluorescent images were captured at $510 \mathrm{~nm}$ every $1.2 \mathrm{~s}$ with an ORCA-03G digital CCD camera (Hamamatsu, Germany).

\section{Statistics}

Data were expressed as mean \pm standard error of the mean (SEM), with $n$ being the number of cell bodies analyzed. Unless otherwise indicated, these cells originate from $\geq 3$ distinct cell cultures. SigmaPlot (version 10.0, Systat Software) was used for plotting graphs and statistical analysis was performed using SigmaStat (version 3.5, Systat Software). The solid line shown in Figure 4B was obtained by a non-linear regression analysis using a sigmoid dose-response curve model. A Student's $t$-test was used to assess the differences between two groups. Differences resulting in $p<0.05$ were regarded as statistically significant.

\section{RESULTS}

\section{STIM and Orai mRNA Expression}

First, the mRNA expression profile of STIM1-2 and Orai1-3 was assessed. mRNAs were extracted from E13 brain cortices and from E13 cortical neurons kept 8 days in vitro (DIV). For STIM, the pattern of mRNA expression was similar in each preparation (cortex and dissociated neurons) with STIM2 being the predominant STIM member (Figure 1). On the other hand, Orail mRNA was barely detectable whereas Orai3 mRNA was found at a low level in the cortex (Figure 1A). In cultured cortical neurons, mRNA expression for both Orai isoforms was hardly significant (Figure 1B) but the Orai2 mRNA was clearly expressed (Figure 1). The bar graph also shows the mRNA expression level of TRPC1, the most abundant TRPC isoform in the E13 cortex (Boisseau et al., 2009). It appears that the mRNAs of the SOC components STIM1-2 and Orai2 predominate over the TRPC1 mRNA.

Next, $\mathrm{Ca}^{2+}$ imaging experiments were conducted to monitor the entry of $\mathrm{Ca}^{2+}$ through native SOCs of cultured E13 cortical neurons. This was done using the $\mathrm{Ca}^{2+}$ add back protocol illustrated in Figure 2: in order to elicit a SOCE, $200 \mathrm{nM}$ thapsigargin (Tg) was applied from time 240 to $600 \mathrm{~s}$ on cells maintained in a $\mathrm{Ca}^{2+}$-free saline to deplete the $\mathrm{ER} \mathrm{Ca}^{2+}$ stores prior to the introduction of $2 \mathrm{mM} \mathrm{Ca}^{2+}$ to the extracellular media at time $600 \mathrm{~s}$. Tg has a high affinity for mammalian $\mathrm{Ca}^{2+}$ pumps of the SERCA but application of micromolar concentrations of this compound can elicit biological responses unrelated to SERCA pumps. Therefore Tg was used at a low concentration to avoid unwanted side effects.

\section{Neuronal SOCE and the STIM2 Inhibitor G418}

The antibiotic G418 has been reported to be a potent STIM2 inhibitor preventing the activation of SOCs like Orail (Parvez et al., 2008). This makes G418 a valuable tool to assess STIM2 functions. In order to probe the relative contribution of STIM1-2 to native neuronal SOCs, experiments were conducted with this antibiotic. Cells were preincubated for $>45 \mathrm{~min}$ at room temperature with $500 \mu \mathrm{g} / \mathrm{mL}$ G418. Under these conditions, G418 did not affect SOCE in embryonic cortical neurons (not shown).

\section{Neuronal SOCE and Blockers of Orai Channels}

To characterize the pharmacological profile of native SOCs, we took advantage of the recent development of blockers of Orai and TRPC channels. The compounds used are listed in Table 2. 

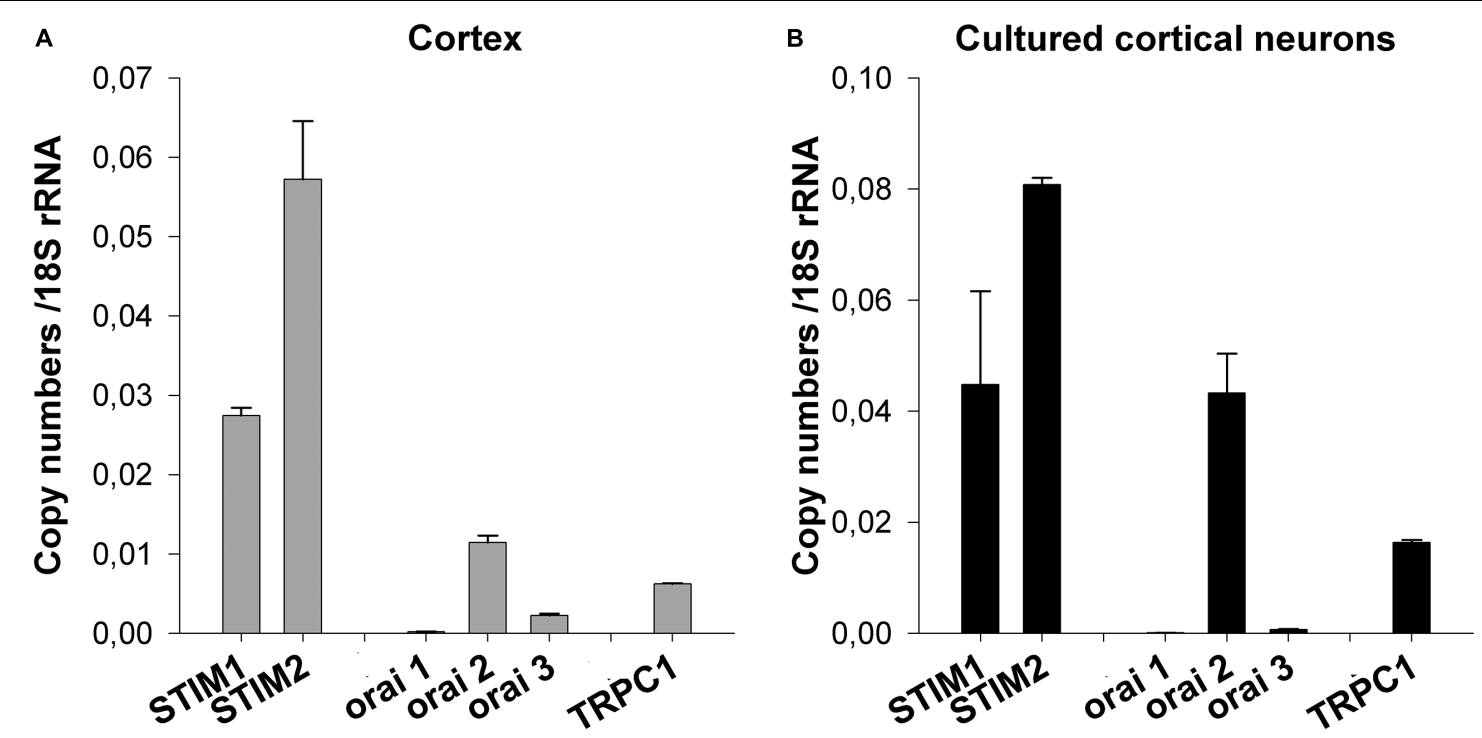

FIGURE 1 | Expression profile of STIM, Orai, and TRPC1 mRNAs. mRNAs were extracted from E13 cortices and from cultured cortical neurons kept in vitro for 8 days. They were analyzed by quantitative real-time RT-PCR. The mRNA expression levels of STIM1, STIM2, Orai1, Orai2, Orai3, and TRPC1 are compared to 18S rRNA. Mean \pm SEM of experiments conducted in triplicate. Profile of mRNA expression in total E13 brain cortices (A) and in dissociated E13 cultured neurons (B).

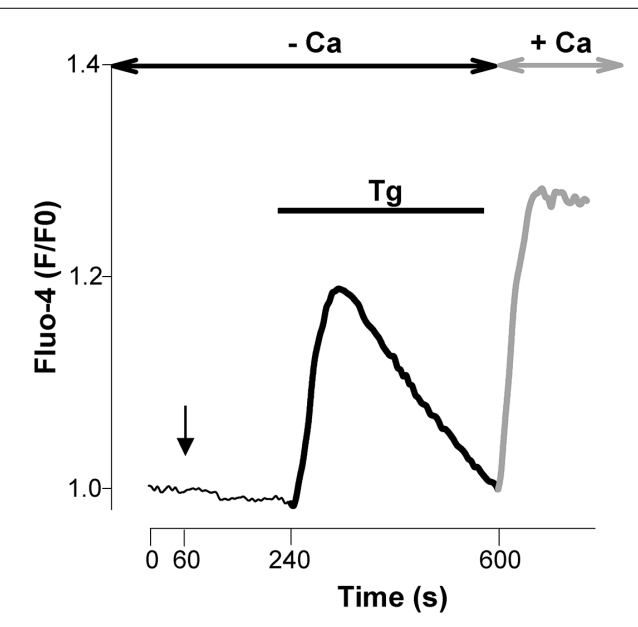

FIGURE 2 | Emptying intracellular pools of $\mathrm{Ca}^{2+}$ with thapsigargin controls an entry of $\mathbf{C a}^{2+}$. Unless otherwise indicated, the experimental protocol used throughout this study is illustrated in this figure. E13 cortical neurons loaded with Fluo-4 were maintained in a $\mathrm{Ca}^{2+}$-free saline.

Thapsigargin ( $\mathrm{Tg}, 200 \mathrm{nM}$ ) was added $240 \mathrm{~s}$ after the beginning of the recording and then washed away prior to the re-admission of $\mathrm{Ca}^{2+}(2 \mathrm{mM})$ into the recording saline medium (at time $600 \mathrm{~s}$ ). Thick dark line: release of $\mathrm{Ca}^{2+}$ evoked by Tg; thick gray line: $\mathrm{Ca}^{2+}$ entry triggered by the emptying of the $\mathrm{Ca}^{2+}$ stores (SOCE). When used, blockers of channels were applied at time $+60 \mathrm{~s}$ (vertical arrow) and remained present till the end of the recording. Antimycin-A was also added at time $+60 \mathrm{~s}$.

For instance, Pyr6 is a newly synthetized pyrazole compound that inhibits Orail-mediated $\mathrm{Ca}^{2+}$ responses with a high potency ( IC $_{50} 0.49 \mu \mathrm{M}$; Schleifer et al., 2012). When applied at the concentration of $1 \mu \mathrm{M}$, Pyr6 reduced the peak amplitude of SOCE by nearly $50 \%$ (Student's $t$-test, $p<0.01$ ) (Figure $3 \mathrm{~A}$ ).
In contrast, Pyr10, another pyrazole compound with a high potency to suppress TRPC3-mediated $\mathrm{Ca}^{2+}$ responses (Schleifer et al., 2012) had no effect when tested at the same concentration $(1 \mu \mathrm{M})$ (Figure 3A). GSK-7975A, another Orai channel blocker, was used. It inhibits Orail- and Orai3-mediated currents with an $\mathrm{IC}_{50}$ of 4.1 and $3.8 \mu \mathrm{M}$, respectively (Derler et al., 2013). As depicted in Figure 3B, $5 \mu \mathrm{M}$ GSK-7975A reduced the peak amplitude of SOCE by $\sim 50 \%$ (filled circles, $p<0.001$, Student's $t$-test). Next, Pyr6 (1 $\mu \mathrm{M})$, and GSK-7975A (5 $\mu \mathrm{M})$ were applied together to see whether they had additive effects. As shown in Figure 3B (open triangles), Pyr6 did not strengthen the blockade of SOCE produced by GSK-7975A alone. These data show that native SOCs of cortical neurons from embryonic mice are sensitive to the Orai channels inhibitors Pyr6 and GSK-7975A, two compounds that have no additive effects.

\section{Neuronal SOCE and Blockers of TRPC Channels}

The exact role played by TRPC channels in the entry of $\mathrm{Ca}^{2+}$ through SOCE is still debated (Prakriya and Lewis, 2015). To clarify this issue, two recent TRPC channel blockers were used: SAR7334, which inhibits TRPC3-, TRPC6-, and TRPC7mediated $\mathrm{Ca}^{2+}$ responses with $\mathrm{IC}_{50}$ values of $282,9.5$, and 226 nM (Maier et al., 2015), respectively, and EVP4593 which targets heteromeric but not homomeric TRPC1 channels ( Wu et al., 2011). A concentration of $1 \mu \mathrm{M}$ EVP4593 reduced the maximal amplitude of SOCE by $\sim 50 \%$ (filled triangles, $p<0.01$, Student's $t$-test) whereas the same concentration of SAR7334 had negligible effects (Figure 3C). In a set of experiments, the Orai channels blocker Pyr6 $(1 \mu \mathrm{M})$ was added together with EVP4593 $(1 \mu \mathrm{M})$. Under this condition, the inhibitory properties of Pyr6 and EVP4593 were only partially additive (open triangles, 
TABLE 2 | Alphabetical list of the Orai and TRPC channel blockers used in this study.

\begin{tabular}{|c|c|c|c|c|c|c|c|}
\hline \multirow[b]{2}{*}{ Compound } & \multicolumn{4}{|c|}{ Over-expression system } & \multicolumn{3}{|c|}{ Native channels } \\
\hline & Cell type & $\begin{array}{l}\text { Over-expressed } \\
\text { proteins }\end{array}$ & $I_{50}$ & Reference & Cell type & $\mathrm{IC}_{50}$ & Reference \\
\hline EVP4593 & $\begin{array}{l}\text { SK-N-SH } \\
\text { neuroblastoma cells }\end{array}$ & TRPC1 & No inhibition & Wu et al., 2011 & Striatal neurons & $\begin{array}{l}\text { SOC inhibited by } \\
40 \% \text { with } 300 \mathrm{nM}\end{array}$ & Wu et al., 2011 \\
\hline \multirow[t]{3}{*}{ GSK-7975A } & HEK cells & $\begin{array}{l}\text { CFP-Stim1/YFP- } \\
\text { Orai1 }\end{array}$ & $4.1 \mu \mathrm{M}$ & Derler et al., 2013 & $\begin{array}{l}\text { Rat basophilic } \\
\text { leukemia } \\
(\mathrm{RBL}-2 \mathrm{H} 3) \text { cells }\end{array}$ & $0.8 \mu \mathrm{M}$ & Derler et al., 2013 \\
\hline & HEK cells & $\begin{array}{l}\text { CFP-Stim1/YFP- } \\
\text { Orai3 }\end{array}$ & $3.8 \mu \mathrm{M}$ & Derler et al., 2013 & & & \\
\hline & HEK cells & YFP-Orai3 & no inhibition & Derler et al., 2013 & & & \\
\hline \multirow[t]{2}{*}{ Pyr3 } & HEK cells & TRPC3 & $0.7 \mu \mathrm{M}$ & Kiyonaka et al., 2009 & $\begin{array}{l}\text { DT40 B } \\
\text { lymphocytes }^{1}\end{array}$ & $\begin{array}{l}\text { Complete inhibition } \\
\text { with } 1 \mu \mathrm{M}\end{array}$ & Kiyonaka et al., 2009 \\
\hline & HEK cells & YFP-TRPC3 & $0.54 \mu \mathrm{M}$ & Schleifer et al., 2012 & RBL-2H3 cells & $0.54 \mu \mathrm{M}$ & Schleifer et al., 2012 \\
\hline Pyr6 & HEK cells & YFP-TRPC3 & $18.46 \mu \mathrm{M}$ & Schleifer et al., 2012 & RBL-2H3 cells & $\begin{array}{l}0.49 \mu \mathrm{M}^{2} \\
\text { (Stim1/Orai1) }\end{array}$ & Schleifer et al., 2012 \\
\hline Pyr10 & HEK cells & YFP-TRPC3 & $0.72 \mu \mathrm{M}$ & Schleifer et al., 2012 & RBL-2H3 cells & $\begin{array}{l}13.08 \mu \mathrm{M} \\
\text { (Stim1/Orai1) }\end{array}$ & Schleifer et al., 2012 \\
\hline \multirow[t]{3}{*}{ SAR7334 } & HEK cells & TRPC3 & $282 \mathrm{nM}$ & Maier et al., 2015 & & & \\
\hline & HEK cells & TRPC6 & $9.5 \mathrm{nM}$ & Maier et al., 2015 & Isolated lungs & $100 \mathrm{nM}^{3}$ & Maier et al., 2015 \\
\hline & HEK cells & TRPC7 & $226 \mathrm{nM}$ & Maier et al., 2015 & & & \\
\hline
\end{tabular}

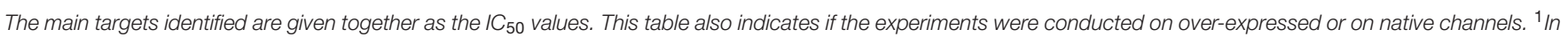

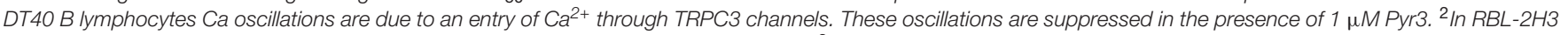

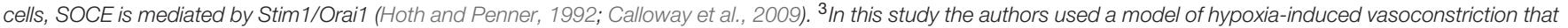
depends exclusively on TRPC6 activity. In isolated lungs, half maximal inhibition of hypoxia-induced vasoconstriction was achieved in the presence of 100 nM SAR7334.

Figure 3C). $\mathrm{Ca}^{2+}$ imaging experiments were also conducted on RBL-2H3 cells where Orail channels are the core components of the native SOCs, without any contribution from TRPC1 channels (Schleifer et al., 2012). When added at 300 nM, EVP4593 significantly reduced the peak amplitude of SOCE in RBL-2H3 cells $(p<0.001$, Figure 3D). This latter observation indicates that EVP4593 has the ability to depress the entry of $\mathrm{Ca}^{2+}$ through Orai channels.

\section{Neuronal SOCE and Extracellular Cations}

Lanthanides like gadolinium $\left(\mathrm{Gd}^{3+}\right)$ ions have been employed as blockers of SOCs. In the murine brain, neuronal SOCE is highly sensitive to $\mathrm{Gd}^{3+}$ (Figure 4A), with the peak amplitude of SOCE being reduced by $\sim 50 \%$ ( $p<0.01$, Student's $t$-test) with $\sim 10 \mathrm{nM}$ $\mathrm{Gd}^{3+}$ (Figure 4B). In some brain areas like the hippocampus and the cortex, neuronal activity can be associated with the release into the synaptic cleft of essential cations like zinc $\left(\mathrm{Zn}^{2+}\right)$ and copper $\left(\mathrm{Cu}^{+/ 2+}\right)$ exerting neuromodulatory actions by acting on diverse neurotransmitter receptors and channels (Bush, 2003). We next addressed the question of the effects of these two cations on native SOCE. As illustrated in Figure 4C, a concentration of $10 \mu \mathrm{M} \mathrm{ZnCl} 2$ (open squares) or $\mathrm{CuCl}_{2}$ (gray triangles) depressed SOCE strongly and equally.

\section{Neuronal SOCE and PLA 2}

Several hypotheses have been put forward to explain how the release of $\mathrm{Ca}^{2+}$ from the ER could activate channels located in the PM. For instance, $\mathrm{Ca}^{2+}$ store depletion would cause the release of a calcium influx factor (CIF) stimulating the activity of the $\mathrm{Ca}^{2+}$-independent phospholipase $\mathrm{A}_{2}\left(\mathrm{iPLA}_{2}\right)$ followed by the activation of SOCs (Smani et al., 2003; Csutora et al., 2006). In order to verify the contribution of $\mathrm{iPLA}_{2}$, experiments were conducted with 2 enantiomers of bromoenol-lactone (BEL), an iPLA 2 inhibitor: (S)-BEL and (R)-BEL, which depress the activity of $\mathrm{iPLA}_{2} \beta$ and $\mathrm{iPLA}_{2} \gamma$, respectively. In smooth muscle cells, (S)-BEL, but not (R)-BEL, depresses SOCE with an $\mathrm{IC}_{50}$ of $\sim 3 \mu \mathrm{M}$ (Csutora et al., 2006). When tested at a concentration of $5 \mu \mathrm{M}$, none of these compounds affected the neuronal SOCE (Figure 5A).

\section{Mitochondrial Regulation of SOCs}

Mitochondria are physiological regulators shaping $\mathrm{Ca}^{2+}$ signals (Pizzo and Pozzan, 2007), notably by buffering $\mathrm{Ca}^{2+}$ ions delivered by plasmalemmal $\mathrm{Ca}^{2+}$ channels, including SOCs (Hoth et al., 1997). It is thought that $\mathrm{Ca}^{2+}$ entering through activated SOCs inhibits their activity. Consequently, impairing the $\mathrm{Ca}^{2+}$ buffering property of mitochondria depresses SOCE (Parekh, 2003). E13 cortical neurons were incubated with antimycin-A, an inhibitor of the mitochondrial electron transport chain. This provoked a strong reduction of SOCE (Figure 5B), which confirms the ability of these organelles to control the $\mathrm{Ca}^{2+}$ signals generated by SOCs.

\section{Resting $\mathrm{Ca}^{2+}$ Entry}

Additional $\mathrm{Ca}^{2+}$ imaging experiments were conducted but without applying thapsigargin. Under this condition, the re-introduction of $\mathrm{Ca}^{2+}$ into the external recording saline 

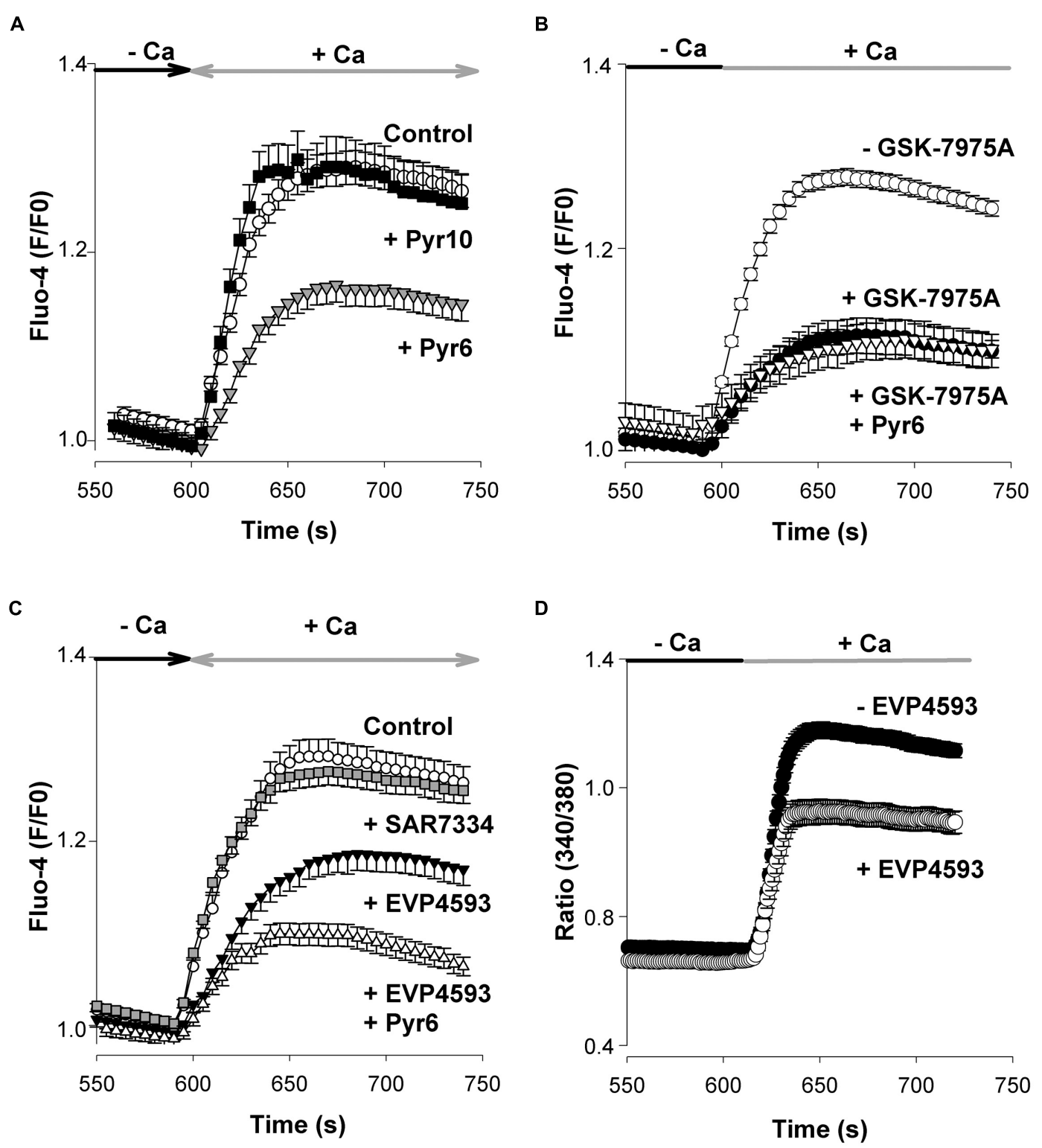

FIGURE 3 | Pyr6, GSK-7975A, and EVP4593 inhibit SOCE but not SAR7334. (A) In these experiments Fluo-4 loaded cells were processed as in Figure 2. Pyr6 (gray triangles, $n=113$ cells) or Pyr10 (filled squares, $n=96$ cells; $1 \mu \mathrm{M}$ ) was added to the saline recording medium at time $+60 \mathrm{~s}$ and remained present till the end of the experiment. Open circles: untreated (control) cells $(n=107)$. (B) Same experiments as in A except $5 \mu$ M GSK-7975A (filled circles, $n=118$ cells), or GSK-7975A $(5 \mu \mathrm{M})+$ Pyr6 $(1 \mu \mathrm{M}$, open triangles, $n=73$ cells, data from 2 cell cultures) were added to the saline at time $+60 \mathrm{~s}$ prior to the application of Tg and remained present throughout the recording. Open circles: untreated (control) cells ( $n=63$ cells). (C) Same protocol as in A except SAR7334 (1 $\mu$ M, gray squares, $n=134$ cells), EVP4593 ( $1 \mu \mathrm{M}$, filled triangles, $n=112$ cells), or EVP4593 ( $1 \mu \mathrm{M})+$ Pyr6 (1 $\mu \mathrm{M}$; open triangles, $n=62$ cells), were added at time +60 s. Open circles: untreated (control) cells $(n=117$ cells). The joint application of EVP4593 $(1 \mu \mathrm{M})+$ Pyr6 $(1 \mu \mathrm{M})$ was tested on two cell cultures. None of the substance tested affected the Tg-evoked $\mathrm{Ca}^{2+}$ response (not shown). (D) EVP4593 depressed SOCE in RBL-2H3 cells. The effect of EVP4593 on native Orai channels from RBL-2H3 was tested by means of Fura-2 $\mathrm{Ca}^{2+}$ imaging experiments according to experimental procedures already described (Schleifer et al., 2012 ). EVP4593 (300 $\mathrm{nM}$, open circles, $n=41$ cells) was added to the saline at time $+60 \mathrm{~s}$ prior to the application of Tg (200 nM) and remained present throughout the recording. Filled circles: Control (EVP4593 untreated) cells $(n=52)$. EVP4593 significantly reduced the peak amplitude of the native SOCE $(p<0.001$, Student's $t$-test). The graphs (A-D) show the last $200 \mathrm{~s}$ of the recording. Mean \pm SEM.

was also followed by an elevation of the Fluo-4 fluorescence amounting to $15-20 \%$ (filled squares, $n=139$ cells) of the peak amplitude of the thapsigargin-activated $\mathrm{Ca}^{2+}$ entry (SOCE, open squares) (Figure 6A). Another key feature of this resting $\mathrm{Ca}^{2+}$ entry is its time course. This is illustrated in Figure 6B where both signals (SOCE and resting $\mathrm{Ca}^{2+}$ entry) have been scaled up. The neuronal SOCE peaked and then slowly declined over time (a run-down which most probably reflects the $\mathrm{Ca}^{2+}$-dependent 


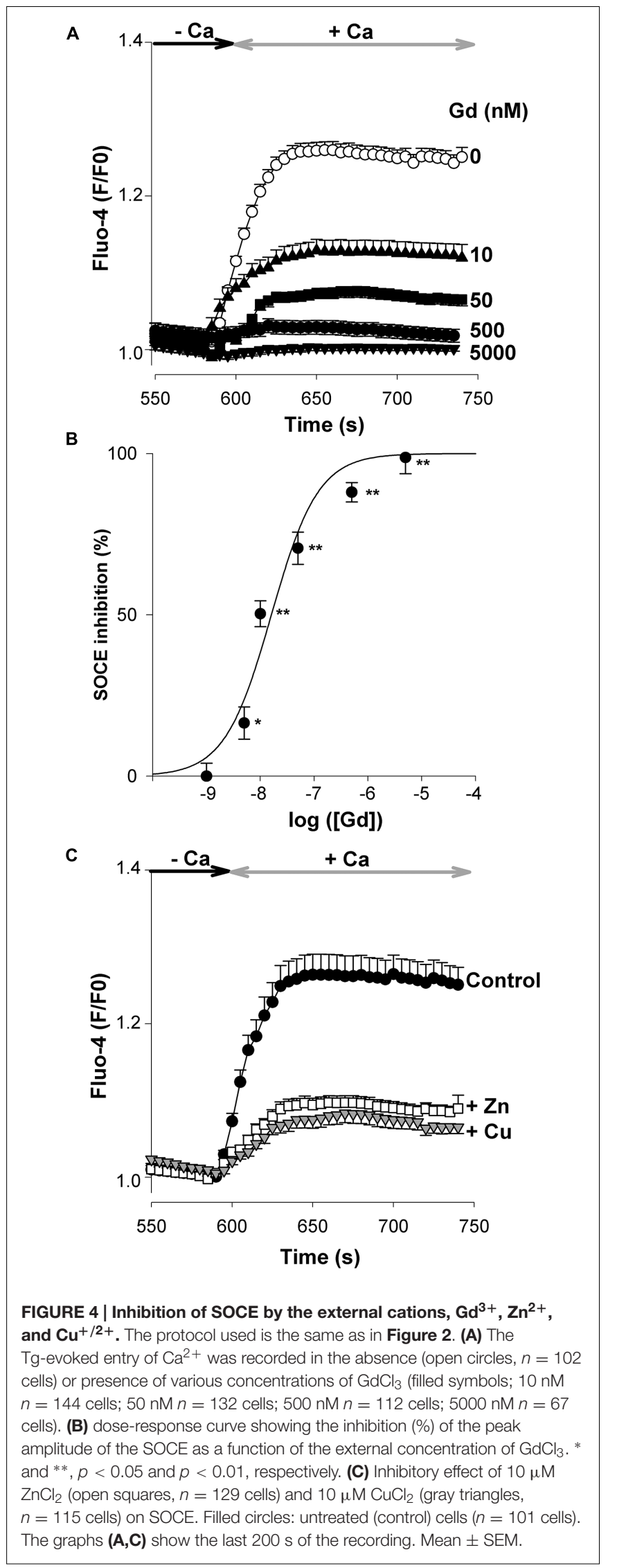

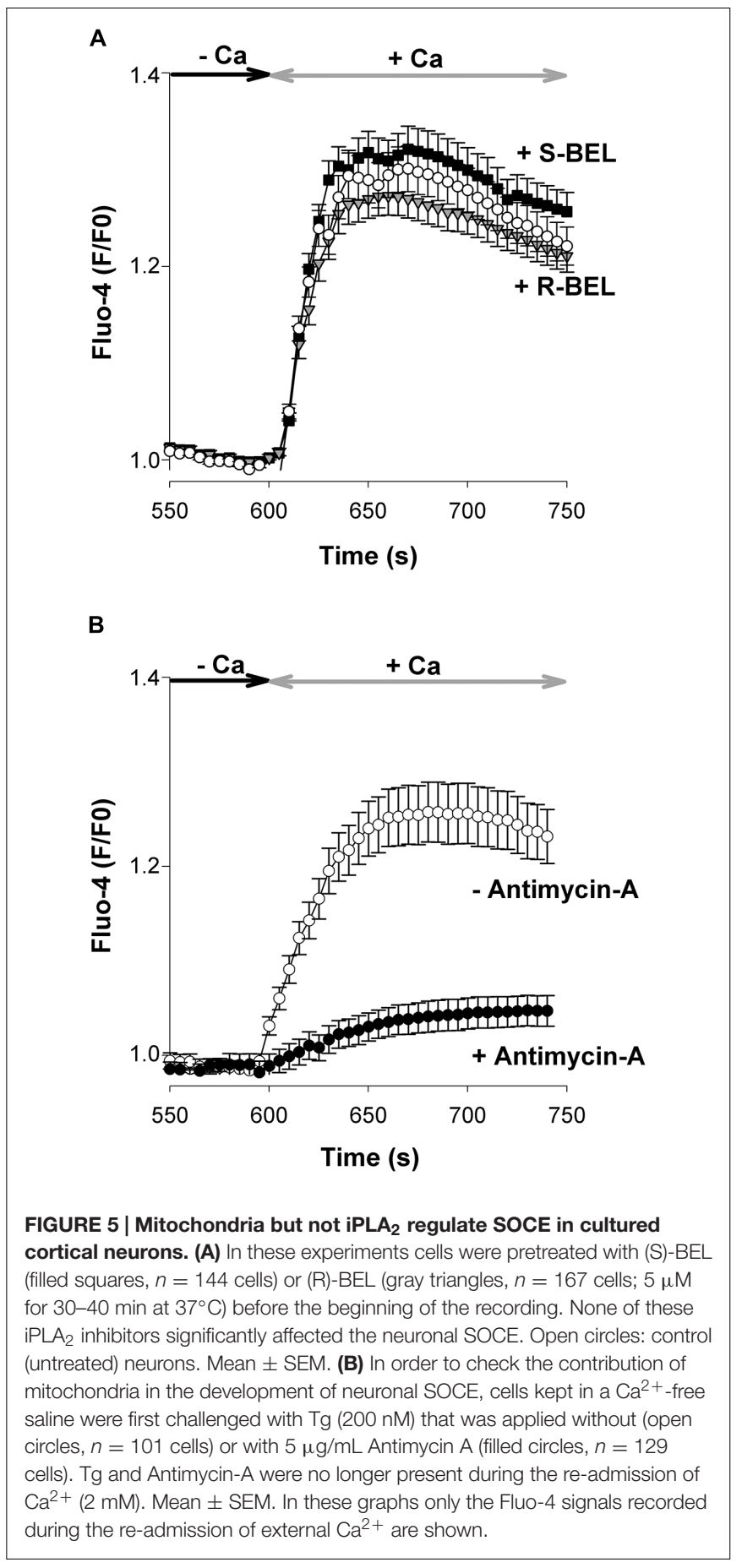

inactivation of the SOCs) whereas the resting $\mathrm{Ca}^{2+}$ entry gave rise to a sustained response (Figure 6B, filled squares). In addition, this resting $\mathrm{Ca}^{2+}$ entry was insensitive to various Orai blockers $\left(10 \mathrm{nM} \mathrm{Gd}{ }^{3+}, n=83\right.$ cells; $1 \mu \mathrm{M}$ Pyr6, $n=89$ cells; $1 \mu \mathrm{M}$ EVP4593, $n=59$ cells; not shown), tested at concentrations that depressed SOCE by $\sim 50 \%$. It was also insensitive to the dihydropyridine nifedipine blocking L-type $\mathrm{Ca}^{2+}$ channels (10 $\mu \mathrm{M}, n=67$ cells; not shown). Therefore, the resting $\mathrm{Ca}^{2+}$ entry and SOCE develop through channels possessing 
A
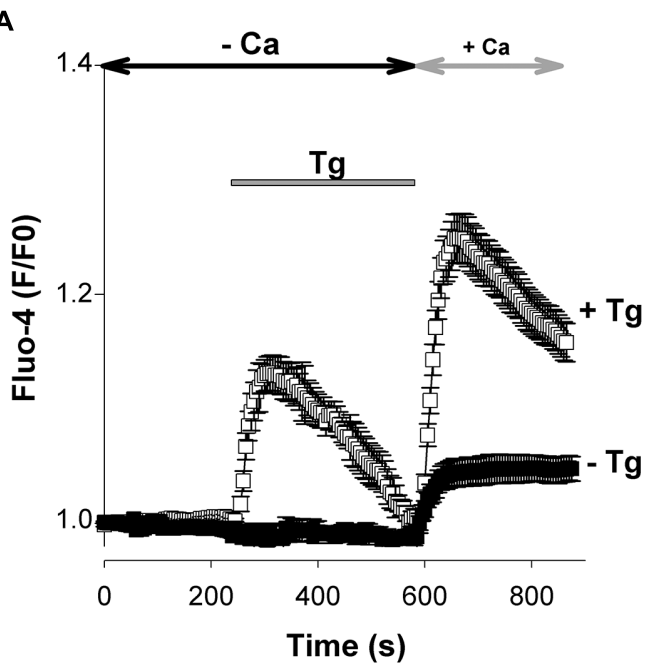

B

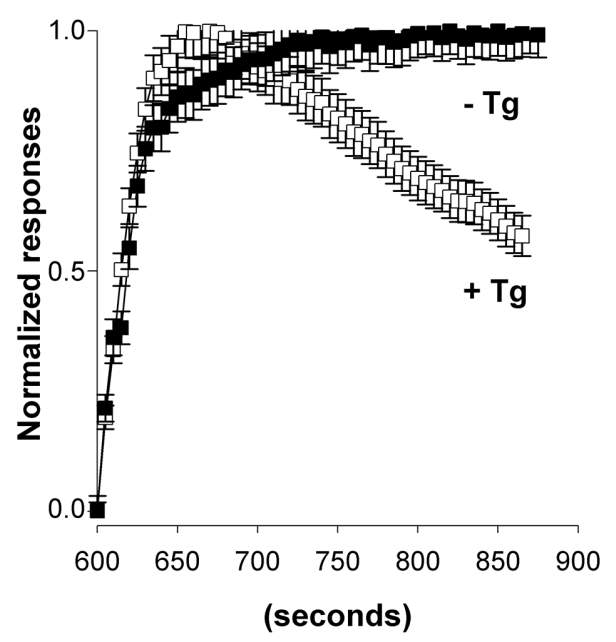

FIGURE 6 | Resting $\mathrm{Ca}^{2+}$ entry and SOCE. (A) Same protocol as in Figure 2. Some neurons were challenged with $\mathrm{Tg}(200 \mathrm{nM}$, open squares, $n=101$ cells) to elicit a SOCE. In another set of experiments, Tg was omitted (filled squares, $n=139$ cells). (B) Same data as in (A; from time +600 to $875 \mathrm{~s})$ after the re-admission of $\mathrm{Ca}^{2+}(2 \mathrm{mM})$ into the external recording saline. Signals have been normalized. Mean \pm SEM.

distinct pharmacological and kinetic properties. Overall, these data indicate that SOCE is mediated by Orai2 channels, the only Orai isoform found in this tissue at that embryonic age, whereas the passive $\mathrm{Ca}^{2+}$ entry seems to develop independently of Orai channels via dihydropyridine-insensitive channels.

\section{DISCUSSION}

This study was initiated to further advance the molecular and pharmacological characterization of native SOCs of embryonic (E13) cortical neurons from murine brains. To this aim, the mRNA expression profile of putative SOC components like STIM1-2 and Orail-3 was assessed by qPCR. In primary cultures of E13 cortical neurons the qPCR analysis failed to detect Orai1 transcripts whereas Orai3 transcripts were only barely detected. Additionally, Orail was also lacking and low levels of Orai3 transcripts were found in the immature cortex. Overall, Orai2 was by far the main Orai mRNA present in the immature E13 cortex and in primary cultures of E13 cortical neurons. STIM1 and STIM2 transcripts were also found in both preparations with STIM2 being the predominant STIM isoform. These results are in line with a previous study showing that STIM2 is the predominant STIM isoform in cultured cortical neurons from E19 rat brain (Gruszczynska-Biegala et al., 2011). Orail is also not found in cultured E18 hippocampal neurons dissociated from mice (Gruszczynska-Biegala et al., 2011) but is detected in cultured E19 cortical neurons from rat brain (Berna-Erro et al., 2009). On the other hand, Orai2 is the only Orai isoform in cultured hippocampal neurons from E18 mice (Berna-Erro et al., 2009). Experiments conducted on Orail knock-out (Orai1 ${ }^{-/-}$) and STIM1 knock-out (STIM1 ${ }^{-/-}$) mice showed that none of these actors contribute to SOCE in the brain (Berna-Erro et al., 2009). Altogether, our qPCR analysis indicates that, in the immature cortex, the principal STIM and Orai transcripts are STIM2 and Orai2. Preliminary immunocytochemical experiments confirmed the expression of Stim 2 and Orai 2 in cultured cortical neurons (Supplementary Figure S1). The accumulated experimental data, whether derived from studies on native neuronal SOCs or from studies on knockout mice, highlight the central role played by STIM2 and Orai2 in neuronal SOC activity.

The pharmacological analysis of native SOCs of E13 cortical neurons shows that they were sensitive to the Orai channel blockers Pyr6 and GSK-7975A. Pyr3, a Orai and TRPC3 channel blocker, was also shown to inhibit native SOCs (Gibon et al., 2010). These channels were neither affected by the TRPC3channel blocker Pyr10 nor by the TRPC3, TRPC6, and TRPC7 channel inhibitor SAR7334. Interestingly, SOCE was depressed by EVP4593, a compound originally described as a blocker of heteromeric TRPC1 channels but having no effect on homomeric TRPC1 channels (Wu et al., 2011), implying that TRPC1 is not a target of EVP4593. We further advance the pharmacological description of EVP5493 action by showing that it depressed native SOCs of RBL-2H3 cells which consist of Orai channels. Interestingly, Pyr6 (described as an Orail blocker) and GSK7975A (described as an Orai3 blocker, see Table 2 for references) exerted the same inhibitory action on native neuronal SOCs whereas Orai2 was the sole Orai channel (at the mRNA level). Furthermore, the effects of Pyr6 and GSK-7975A were not additive, indicating they act on a common target. However, a joint addition of Pyr6 + EVP4593, tested at concentrations reducing the peak SOCE by half, did not fully block SOCE, their effects being partially additive. Based on this finding it is tempting to propose that TRPC1, together with Orai proteins, is involved in neuronal SOC. Of note, TRPC1, at the mRNA level, is the most abundant TRPC found in the E13 murine brain and cortex (Boisseau et al., 2009). However, this view derived from a pharmacological analysis is hypothetical and it remains to be shown whether TRPC1 assembles with Orai2 to form neuronal SOCs. 
Store-operated channels are highly sensitive to lanthanides like gadolinium $\left(\mathrm{Gd}^{3+}\right)$. These cations can thus be used to discriminate SOCs from other $\mathrm{Ca}^{2+}$-conducting channels such as TRPC and voltage-gated $\mathrm{Ca}^{2+}$ channels which require micromolar amounts of $\mathrm{Gd}^{3+}$ for blockade. In the embryonic brain, native SOCs displayed a high sensitivity to $\mathrm{Gd}^{3+}$ which abolishes SOCE with an $\mathrm{IC}_{50}$ of $\sim 10 \mathrm{nM}$. Of note, $\mathrm{Gd}^{3+}$ ions block CRAC (a subtype of SOCs formed by Orai proteins) with $\mathrm{IC}_{50}$ values of 28 and $50 \mathrm{nM}$ in thymocytes and drosophila S2 cells, respectively (Ross and Cahalan, 1995; Yeromin et al., 2004). This high sensitivity of neuronal SOCs to $\mathrm{Gd}^{3+}$ further suggests that Orai, and not TRPC, channels contribute to SOCE in this cell type. SOCs of embryonic cortical neurons were depressed by $\mathrm{Zn}^{2+}$ and $\mathrm{Cu}^{+/ 2+}$, two essential cations that can be released synaptically upon neuronal stimulation (Bush, 2003). In our experiments, $10 \mu \mathrm{M} \mathrm{ZnCl}_{2}$ (or $\mathrm{CuCl}_{2}$ ) strongly depresses SOCE. This indicates that synaptic SOCs are likely to be down-regulated at active synapses releasing $\mathrm{Zn}^{2+}$ and/or $\mathrm{Cu}^{+/ 2+}$.

The contribution of $\mathrm{iPLA}_{2}$ in SOCE has been shown for SOCs composed of STIM1 and Orail in smooth muscle cells and RBL cells (Bolotina, 2008). However, in embryonic cortical neurons, the pharmacological inhibition of $\operatorname{iPLA}_{2} \beta$ [with (S)$\mathrm{BEL}$ ] or $\mathrm{iPLA}_{2} \gamma$ [with (R)-BEL] was not associated with any impairment of SOCE. Of note, BEL blocks $\mathrm{Ca}^{2+}$ entry through voltage-gated $\mathrm{Ca}^{2+}$ channels and TRPC1, TRPC5, and TRPC6 channels with $\mathrm{IC}_{50}$ values of $7-8 \mu \mathrm{M}$ (Chakraborty et al., 2011). Another interesting property of native neuronal SOCs is their regulation by mitochondria. Indeed, Antimycin A, which depolarizes mitochondria and prevents the mitochondrial $\mathrm{Ca}^{2+}$ uptake, strongly depressed the entry of $\mathrm{Ca}^{2+}$ though SOCs. These channels, like other types of $\mathrm{Ca}^{2+}$ channels, are subject to a $\mathrm{Ca}^{2+}$ dependent inactivation process which down regulates the influx of $\mathrm{Ca}^{2+}$. By buffering $\mathrm{Ca}^{2+}$ ions entering via SOCs, mitochondria modulate $\mathrm{Ca}^{2+}$ microdomains, precluding, or minimizing the $\mathrm{Ca}^{2+}$-dependent inactivation of SOCs, permitting larger influx of $\mathrm{Ca}^{2+}$ to occur (Parekh, 2003).

\section{CONCLUSION}

Our data indicate that Orai2 is a critical pore component of native neuronal SOCs in the immature cortex. They are sensitive to various Orai blockers like Pyr6 and GSK-7975A. These channels

\section{REFERENCES}

Berna-Erro, A., Braun, A., Kraft, R., Kleinschnitz, C., Schuhmann, M. K., Stegner, D., et al. (2009). STIM2 regulates capacitive Ca2+ entry in neurons and plays a key role in hypoxic neuronal cell death. Sci. Signal. 2:ra67. doi: 10.1126/scisignal.2000522

Birnbaumer, L. (2009). The TRPC class of ion channels: a critical review of their roles in slow, sustained increases in intracellular $\mathrm{Ca}(2+)$ concentrations. Annu. Rev. Pharmacol. Toxicol. 49, 395-426. doi: 10.1146/annurev.pharmtox.48. 113006.094928

Boisseau, S., Kunert-Keil, C., Lucke, S., and Bouron, A. (2009). Heterogeneous distribution of TRPC proteins in the embryonic cortex. Histochem. Cell Biol. 131, 355-363. doi: 10.1007/s00418-008-0532-6 are also blocked by EVP4593, and the cations $\mathrm{Gd}^{3+}, \mathrm{Zn}^{2+}$, and $\mathrm{Cu}^{+/ 2+} \cdot \mathrm{Gd}^{3+}$ cations are by far the most potent neuronal SOCs blocker tested. Of note, none of the Orai channel blockers used (Pyr6, GSK-7975A) can be employed to discriminate native Orai channels since they inhibit all types of Orai channels. Mitochondria are controlling SOCE which seems to develop without the requirement of $\mathrm{iPLA}_{2}$ activity. On the other hand, the passive entry of $\mathrm{Ca}^{2+}$ exhibit distinct pharmacological and kinetics profiles indicating that they deliver $\mathrm{Ca}^{2+}$ to neurons via channels distinct from SOCs. The presence of functional SOCs at the beginning of cortico-genesis suggests that this $\mathrm{Ca}^{2+}$ route is likely to play a role in the formation of the brain cortex.

\section{AUTHOR CONTRIBUTIONS}

SC performed experiments and analyzed data. LJ performed experiments and analyzed data. NS performed experiments and analyzed data. MC performed experiments and analyzed data. KG contributed new reagents. AB designed the study, performed experiments, analyzed data and wrote the manuscript.

\section{ACKNOWLEDGMENTS}

The authors wish to thank the Centre National de la Recherche Scientifique for its support. They also wish to thank Dr Malcolm Begg (GlaxoSmithKline) and Sanofi-Aventis Deutschland for the gifts of hyperforin, GSK-7975A, and SAR7334, respectively. We also thank L. Macari for her help with the cell cultures. LJ was funded by a University of Florida studentship (Howard Hughes Medical Institute Science for Life extramural award).

\section{SUPPLEMENTARY MATERIAL}

The Supplementary Material for this article can be found online at: http://journal.frontiersin.org/article/10.3389/fphar. 2016.00486/full\#supplementary-material

FIGURE S1 | Detection of Stim1, Stim2, Orai1, Orai2, Orai3 by immunocytochemistry.

Bolotina, V. M. (2008). Orai, STIM1 and iPLA2beta: a view from a different perspective. J. Physiol. 586, 3035-3042. doi: 10.1113/jphysiol.2008. 154997

Bouron, A. (2000). Activation of a capacitative $\mathrm{Ca}(2+)$ entry pathway by store depletion in cultured hippocampal neurones. FEBS Lett. 470, 269-272. doi: 10.1016/S0014-5793(00)01340-5

Bouron, A., Altafaj, X., Boisseau, S., and De Waard, M. (2005). A store-operated $\mathrm{Ca} 2+$ influx activated in response to the depletion of thapsigargin-sensitive $\mathrm{Ca} 2+$ stores is developmentally regulated in embryonic cortical neurons from mice. Brain Res. Dev. Brain Res. 159, 64-71. doi: 10.1016/j.devbrainres.2005.07. 001

Bush, A. I. (2003). The metallobiology of Alzheimer's disease. Trends Neurosci. 26, 207-214. doi: 10.1016/S0166-2236(03)00067-5 
Calloway, N., Vig, M., Kinet, J.-P., Holowka, D., and Baird, B. (2009). Molecular clustering of STIM1 with Orail/CRACM1 at the plasma membrane depends dynamically on depletion of $\mathrm{Ca}^{2+}$ stores and on electrostatic interactions. Mol. Biol. Cell 20, 389-399. doi: 10.1091/mbc.E07-11-1132

Chakraborty, S., Berwick, Z. C., Bartlett, P. J., Kumar, S., Thomas, A. P., Sturek, M., et al. (2011). Bromoenol lactone inhibits voltage-gated $\mathrm{Ca} 2+$ and transient receptor potential canonical channels. J. Pharmacol. Exp. Ther. 339, 329-340. doi: 10.1124/jpet.111.183673

Chauvet, S., Boonen, M., Chevallet, M., Jarvis, L., Abebe, A., Benharouga, M., et al. (2015). The Na+/K+-ATPase and the amyloid-beta peptide abetal-40 control the cellular distribution, abundance and activity of TRPC6 channels. Biochim. Biophys. Acta 1853(11 Pt A), 2957-2965. doi: 10.1016/j.bbamcr.2015. 09.004

Cheng, K. T., Ong, H. L., Liu, X., and Ambudkar, I. S. (2013). Contribution and regulation of TRPC channels in store-operated Ca2+ entry. Curr. Top. Membr. 71, 149-179. doi: 10.1016/B978-0-12-407870-3.00007-X

Clementi, E., Scheer, H., Zacchetti, D., Fasolato, C., Pozzan, T., and Meldolesi, J. (1992). Receptor-activated Ca2+ influx. Two independently regulated mechanisms of influx stimulation coexist in neurosecretory PC12 cells. J. Biol. Chem. 267, 2164-2172.

Csutora, P., Zarayskiy, V., Peter, K., Monje, F., Smani, T., Zakharov, S. I., et al. (2006). Activation mechanism for CRAC current and store-operated $\mathrm{Ca} 2+$ entry: calcium influx factor and $\mathrm{Ca} 2+$-independent phospholipase A2beta-mediated pathway. J. Biol. Chem. 281, 34926-34935. doi: 10.1074/jbc. M606504200

Derler, I., Schindl, R., Fritsch, R., Heftberger, P., Riedl, M. C., Begg, M., et al. (2013). The action of selective CRAC channel blockers is affected by the Orai pore geometry. Cell Calcium 53, 139-151. doi: 10.1016/j.ceca.2012. 11.005

Gibon, J., Deloulme, J. C., Chevallier, T., Ladeveze, E., Abrous, D. N., and Bouron, A. (2013). The antidepressant hyperforin increases the phosphorylation of CREB and the expression of TrkB in a tissuespecific manner. Int. J. Neuropsychopharmacol. 16, 189-198. doi: 10.1017/ S146114571100188X

Gibon, J., Tu, P., and Bouron, A. (2010). Store-depletion and hyperforin activate distinct types of $\mathrm{Ca}(2+)$-conducting channels in cortical neurons. Cell Calcium 47, 538-543. doi: 10.1016/j.ceca.2010.05.003

Gruszczynska-Biegala, J., Pomorski, P., Wisniewska, M. B., and Kuznicki, J. (2011). Differential roles for STIM1 and STIM2 in store-operated calcium entry in rat neurons. PLoS ONE 6:e19285. doi: 10.1371/journal.pone. 0019285

Hoth, M., Fanger, C. M., and Lewis, R. S. (1997). Mitochondrial regulation of store-operated calcium signaling in T lymphocytes. J. Cell Biol. 137, 633-648. doi: $10.1083 /$ jcb.137.3.633

Hoth, M., and Niemeyer, B. A. (2013). The neglected CRAC proteins: Orai2, Orai3, and STIM2. Curr. Top. Membr. 71, 237-271. doi: 10.1016/B978-0-12-4078703.00010-X

Hoth, M., and Penner, R. (1992). Depletion of intracellular calcium stores activates a calcium current in mast cells. Nature 355, 353-356. doi: 10.1038/355 $353 \mathrm{a} 0$

Kiyonaka, S., Kato, K., Nishida, M., Mio, K., Numaga, T., Sawaguchi, Y., et al. (2009). Selective and direct inhibition of TRPC 3 channels underlies biological activities of a pyrazole compound. Proc. Natl. Acad. Sci. U.S.A. 106, 5400-5405. doi: $10.1073 /$ pnas.0808793106

Lee, K. P., Yuan, J. P., Hong, J. H., So, I., Worley, P. F., and Muallem, S. (2010). An endoplasmic reticulum/plasma membrane junction: STIM1/Orai1/TRPCs. FEBS Lett. 584, 2022-2027. doi: 10.1016/j.febslet.2009. 11.078

Maier, T., Follmann, M., Hessler, G., Kleemann, H. W., Hachtel, S., Fuchs, B., et al. (2015). Discovery and pharmacological characterization of a novel potent inhibitor of diacylglycerol-sensitive TRPC cation channels. Br. J. Pharmacol. 172, 3650-3660. doi: 10.1111/bph.13151

Mathes, C., and Thompson, S. H. (1994). Calcium current activated by muscarinic receptors and thapsigargin in neuronal cells. J. Gen. Physiol. 104, 107-121. doi: 10.1085/jgp.104.1.107

Parekh, A. B. (2003). Store-operated Ca2+ entry: dynamic interplay between endoplasmic reticulum, mitochondria and plasma membrane. J. Physiol. 547, 333-348. doi: 10.1113/jphysiol.2002.034140
Parvez, S., Beck, A., Peinelt, C., Soboloff, J., Lis, A., Monteilh-Zoller, M., et al. (2008). STIM2 protein mediates distinct store-dependent and storeindependent modes of CRAC channel activation. FASEB J. 22, 752-761. doi: 10.1096/fj.07-9449com

Pfaffl, M. W. (2001). A new mathematical model for relative quantification in real-time RT-PCR. Nucleic Acids Res. 29:e45. doi: 10.1093/nar/29.9.e45

Pizzo, P., and Pozzan, T. (2007). Mitochondria-endoplasmic reticulum choreography: structure and signaling dynamics. Trends Cell Biol. 17, 511-517. doi: 10.1016/j.tcb.2007.07.011

Prakriya, M., and Lewis, R. S. (2015). Store-operated calcium channels. Physiol. Rev. 95, 1383-1436. doi: 10.1152/physrev.00020.2014

Prothero, L. S., Mathie, A., and Richards, C. D. (2000). Purinergic and muscarinic receptor activation activates a common calcium entry pathway in rat neocortical neurons and glial cells. Neuropharmacology 39, 1768-1778. doi: 10.1016/S0028-3908(00)00013-7

Putney, J. W. Jr. (1986). A model for receptor-regulated calcium entry. Cell Calcium 7, 1-12. doi: 10.1016/0143-4160(86)90026-6

Ross, P. E., and Cahalan, M. D. (1995). Ca2+ influx pathways mediated by swelling or stores depletion in mouse thymocytes. J. Gen. Physiol. 106, 415-444. doi: 10.1085/jgp.106.3.415

Schleifer, H., Doleschal, B., Lichtenegger, M., Oppenrieder, R., Derler, I., Frischauf, I., et al. (2012). Novel pyrazole compounds for pharmacological discrimination between receptor-operated and store-operated $\mathrm{Ca}(2+)$ entry pathways. Br. J. Pharmacol. 167, 1712-1722. doi: 10.1111/j.1476-5381.2012. 02126.x

Smani, T., Zakharov, S. I., Leno, E., Csutora, P., Trepakova, E. S., and Bolotina, V. M. (2003). Ca2+-independent phospholipase A2 is a novel determinant of store-operated Ca2+ entry. J. Biol. Chem. 278, 11909-11915. doi: 10.1074/jbc. M210878200

Takahashi, T., Nowakowski, R. S., and Caviness, V. S. Jr. (1995). Early ontogeny of the secondary proliferative population of the embryonic murine cerebral wall. J. Neurosci. 15, 6058-6068.

Takemura, H., Ohshika, H., Yokosawa, N., Oguma, K., and Thastrup, O. (1991). The thapsigargin-sensitive intracellular $\mathrm{Ca} 2+$ pool is more important in plasma membrane $\mathrm{Ca} 2+$ entry than the IP3-sensitive intracellular $\mathrm{Ca} 2+$ pool in neuronal cell lines. Biochem. Biophys. Res. Commun. 180, 1518-1526. doi: 10. 1016/S0006-291X(05)81368-3

Tu, P., Gibon, J., and Bouron, A. (2010). The TRPC6 channel activator hyperforin induces the release of zinc and calcium from mitochondria. J. Neurochem. 112, 204-213. doi: 10.1111/j.1471-4159.2009.06446.x

Usachev, Y. M., and Thayer, S. A. (1999). Ca2+ influx in resting rat sensory neurones that regulates and is regulated by ryanodine-sensitive $\mathrm{Ca} 2+$ stores. J. Physiol. 519(Pt 1), 115-130. doi: 10.1111/j.1469-7793.1999.0115o.x

Wu, J., Shih, H. P., Vigont, V., Hrdlicka, L., Diggins, L., Singh, C., et al. (2011). Neuronal store-operated calcium entry pathway as a novel therapeutic target for Huntington's disease treatment. Chem. Biol. 18, 777-793. doi: 10.1016/j.ch embiol.2011.04.012

Yeromin, A. V., Roos, J., Stauderman, K. A., and Cahalan, M. D. (2004). A storeoperated calcium channel in Drosophila S2 cells. J. Gen. Physiol. 123, 167-182. doi: 10.1085 /jgp. 200308982

Yoo, A. S., Cheng, I., Chung, S., Grenfell, T. Z., Lee, H., Pack-Chung, E., et al. (2000). Presenilin-mediated modulation of capacitative calcium entry. Neuron 27, 561-572. doi: 10.1016/S0896-6273(00)00066-0

Zufall, F., Leinders-Zufall, T., and Greer, C. A. (2000). Amplification of odorinduced $\mathrm{Ca}(2+)$ transients by store-operated $\mathrm{Ca}(2+)$ release and its role in olfactory signal transduction. J. Neurophysiol. 83, 501-512.

Conflict of Interest Statement: The authors declare that the research was conducted in the absence of any commercial or financial relationships that could be construed as a potential conflict of interest.

Copyright $\odot 2016$ Chauvet, Jarvis, Chevallet, Shrestha, Groschner and Bouron. This is an open-access article distributed under the terms of the Creative Commons Attribution License (CC BY). The use, distribution or reproduction in other forums is permitted, provided the original author(s) or licensor are credited and that the original publication in this journal is cited, in accordance with accepted academic practice. No use, distribution or reproduction is permitted which does not comply with these terms. 